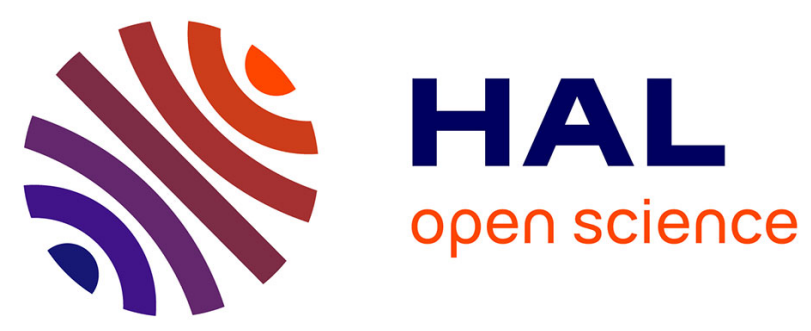

\title{
Potentialities of Air-Filled Substrate Integrated Waveguides based on Carbon Nanotubes in E-band 1
}

Phi Long Doan, Emmanuel Pistono, Philippe Coquet, Jianxiong Wang, Florence Podevin, Dominique Baillargeat, Joseph de Saxcé, Stéphane Bila

\section{- To cite this version:}

Phi Long Doan, Emmanuel Pistono, Philippe Coquet, Jianxiong Wang, Florence Podevin, et al.. Potentialities of Air-Filled Substrate Integrated Waveguides based on Carbon Nanotubes in E-band 1. IEEE MTT-S International Conference on Microwaves for Intelligent Mobility (ICMIM 2020), Apr 2020, Linz (en virtuel), Austria. hal-03047743

\section{HAL Id: hal-03047743 \\ https: / hal-unilim.archives-ouvertes.fr/hal-03047743}

Submitted on 8 Dec 2020

HAL is a multi-disciplinary open access archive for the deposit and dissemination of scientific research documents, whether they are published or not. The documents may come from teaching and research institutions in France or abroad, or from public or private research centers.
L'archive ouverte pluridisciplinaire HAL, est destinée au dépôt et à la diffusion de documents scientifiques de niveau recherche, publiés ou non, émanant des établissements d'enseignement et de recherche français ou étrangers, des laboratoires publics ou privés. 


\section{Potentialities of Air-Filled Substrate Integrated Waveguides based on Carbon Nanotubes in E-band}

\author{
${ }^{1}$ Phi Long Doan, \\ ${ }^{2}$ Emmanuel Pistono \\ Univ. Grenoble Alpes, \\ RFIC-Lab, \\ 38000 Grenoble, France \\ 1.phi-long.doan@univ-grenoble-alpes.fr \\ 2 emmanuel.pistono@univ-grenoble- \\ alpes.fr
}

\author{
${ }^{3}$ Philippe Coquet, \\ ${ }^{4}$ Jianxiong Wang \\ Nanyang Technological University, \\ CINTRA CNRS/NTU/Thales \\ UMI 3288, 50 Nanyang Drive, \\ Singapore \\ 3 philippe.Coquet@cnrs.fr \\ 4jxwang@ntu.edu.sg
}

Florence Podevin

Univ. Grenoble Alpes, Grenoble INP*, RFIC-Lab,

* Institute of Engineering Univ. Grenoble Alpes

38000 Grenoble, France

florence.podevin@univ-grenoble-

\author{
${ }^{5}$ Dominique Baillargeat, \\ ${ }^{6}$ Joseph de Saxce, ${ }^{7}$ Stéphane Bila \\ University of Limoges/CNRS, \\ XLIM UMR7252, \\ 123 Av A Thomas, 87000 Limoges \\ 5ominique.baillargeat@xlim.fr. \\ joseph.de-saxce@xlim.fr. \\ ${ }_{\text {stephane.bila@xlim.fr }}$
}

\begin{abstract}
This paper describes a classic architecture of a $4 \times 4$ Butler matrix in an innovative air-filled waveguide technology based on carbon nanotubes for beam pointing or beam tracking activities for $5 \mathrm{G}$ applications. The working frequencies concern particularly the E-band $(71-86 \mathrm{GHz})$. The model used to simulate the waveguides, couplers and crossovers needed for the Butler matrix is presented as well as the expected results in terms of $S$ parameters. The expected insertion loss is extremely low thanks to the considered technology, $0.02 \mathrm{~dB} / \mathrm{mm}$ in E-band, making the carbon nanotubes very attractive in this context. The transitions that allow connecting the waveguides to planar transmission lines have also been developed and are introduced in this paper. Their maximum insertion losses are 0.6 dB for a matching better than $17 \mathrm{~dB}$ over the entire E-band.
\end{abstract}

Index Terms- Air-filled substrate integrated waveguide, carbon nanotube, Butler matrix, E-band, $5 G$ application.

\section{INTRODUCTION}

Recently, the available bands for wireless communication systems have become increasingly restricted because the individual demand for the data transfer has increased rapidly [1]. Therefore, a new spectrum band need to be unlocked. It has been widely demonstrated that the E-band (71-86 GHz) could be an interesting candidate for this issue, considering the large bandwidths that can be implemented for improving the channel capacity as well as for enabling very high data rate [2]. As a major concern, telecom operators are now turning towards this band, which is called "Next Generation Wireless Backhaul Spectrum" [3]. Practically, the E-band is divided into four sub-bands $71-76 \mathrm{GHz}$ and $81-86 \mathrm{GHz}$ for the $5 \mathrm{G}$ backhaul, $76-77 \mathrm{GHz}$ for the long-range radar systems and $77-81 \mathrm{GHz}$ for the short-range and average-range radar systems.

However, increasing the working frequency leads to the increase of transmission loss [1]. It is then necessary to focus on antenna networks allowing a wide spatial coverage while presenting a significant gain [4]. In this context, we proposed to optimize a Butler matrix (BM) in an air-filled substrate integrated waveguide (AFSIW) technology [5] by making the lateral walls with forests of carbon nanotubes (CNTs) which is extremely promising in terms of losses. After reminding the BM principle in section II and describing the model used for CNTs in section III, the simulation results of the waveguides, 3-dB couplers, crossovers and BM as well as the essential of using SIW-to-CPW transition at the input/output of the BM will be presented in section IV, V and VI.

\section{CONFIGURATION OF BUtLER MATRIX}

The principle of a $4 \times 4$ BM (see Fig. 1) consists of four 3$\mathrm{dB}$ couplers, two crossovers and two pairs of phase shifters. It allows imposing a constant phase difference between two consecutive output ports by choosing the correct input port, each of the output ports ( 5 to 8 ) having a quarter $(-6 \mathrm{~dB})$ of the input signal. The phase differences between output ports are given in Table 1. They correspond to the phase shifters in Fig. $1\left(45^{\circ}\right.$ and $\left.0^{\circ}\right)$. Then, the output ports can feed the four radiating elements of an antenna array allowing then the steering of the radiating pattern.

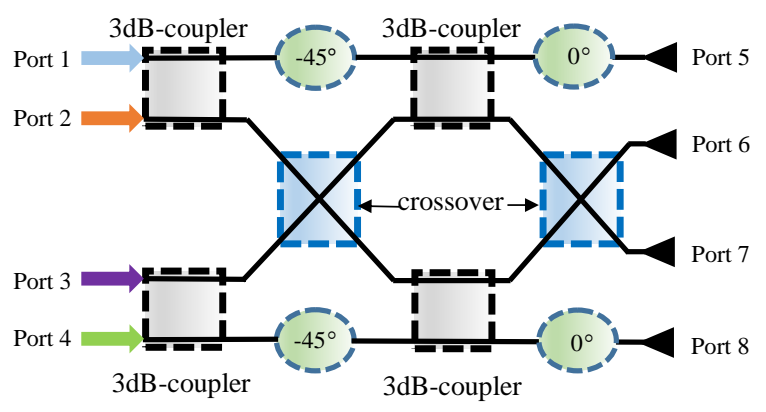

Fig. 1. Block diagram of a $4 \times 4$ Butler Matrix.

TABLE I. RELATIONSHIPS BETWEEN FEEDING PORTS AND OUTPUT PHASE DIFFERENCES

\begin{tabular}{|c|c|c|c|c|}
\hline Feeding port & Port 1 & Port 2 & Port 3 & Port 4 \\
\hline Output phase difference & $-45^{\circ}$ & $135^{\circ}$ & $-135^{\circ}$ & $45^{\circ}$ \\
\hline
\end{tabular}

The important parameters, besides insertion losses, are the isolation between ports and the matching of each block to avoid multiple reflections within the system.

\section{CARbon Nanotube Modeling}

The air-filled waveguides, formed by connecting CNTlateral walls with the horizontal metal walls, as in Fig. 2(a), were modeled by using a full-wave simulator (HFSS). In 
order to simulate electromagnetically the $3 \mathrm{D}$ waveguides, a "bulk material" equivalent model of the CNT forest, described in [6], is used. Such a model is defined by a complex axial conductivity, with no horizontal conductivity, for a specific number of parallel CNT aligned along the CNTaxis:

$$
\sigma_{\text {Axial }}(q, \omega)=D_{N T} * \frac{8 * e^{2} * v_{F}}{h *(v+j \omega)}
$$

where $\boldsymbol{\omega}$ is the angular frequency, $\boldsymbol{e} \approx \mathbf{1 . 6 0 2} * \mathbf{1 0}^{-19} \boldsymbol{C}$ is the elementary charge, $\boldsymbol{h} \approx \mathbf{6 . 6 2 6} * \mathbf{1 0}^{-\mathbf{3 4}} \mathrm{J} . \boldsymbol{s}$ is the Plank constant, $v_{F}=\mathbf{9 . 7 1} * 10^{5} \mathrm{~m} / \mathrm{s}$ is the Fermi velocity in CNTs, $\boldsymbol{v}=\boldsymbol{\tau}^{\mathbf{- 1}}$ is the relaxation frequency with $\tau \approx 3 * \mathbf{1 0}^{-\mathbf{1 2}} s$ and $D_{N T}$ is the density of the CNT, typically $\mathbf{1 0}^{\mathbf{1 4}}$ per $\boldsymbol{m}^{2}$. It corresponds to a valeur of $\sigma_{\text {Axial }}(q, \omega)$ equals to $9,03 * 10^{4} \mathrm{~S} / \mathrm{m}$.

The different blocks in Fig. 1 have been optimized based on this model, for a height of CNT of $300 \mu \mathrm{m}$. The CNTbased AFSIW with a width of $2.98 \mathrm{~mm}$ leads to a cut-off frequency of $52 \mathrm{GHz}$.

\section{CNT-Based Afsiw Waveguide And Its Planar ACCESS}

\section{A. Stack of the considered technology}

An exploded view of the investigated CNT-based AFSIW waveguide is illustrated in Fig.2. This waveguide consists of three layers: (i) a bottom metallic layer etched on a dielectric substrate ROGERS RT Duroid 5880 (with a thickness of $0.127 \mathrm{~mm}$ and a relative dielectric permittivity of 2.2) to define the feeding lines and matching slots, (ii) the CNT walls transferred on the bottom metallic layer by using flip-chip process to form the lateral wall of the waveguide, and (iii) the top metallic cover layer. Notice that to avoid the appearance of substrate modes within the E-band, a thin bottom substrate thickness $(0.127 \mathrm{~mm})$ is considered.

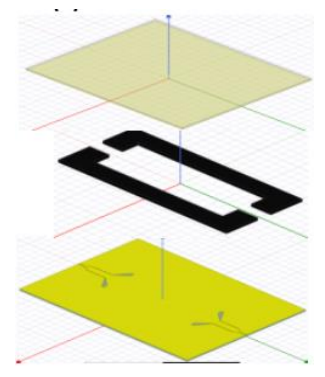

Top layer (metallic cover)

CNT layer (lateral wall of SIW waveguide)

Bottom layer (access line, coupling slot, metallic plan (a) of SIW waveguide)

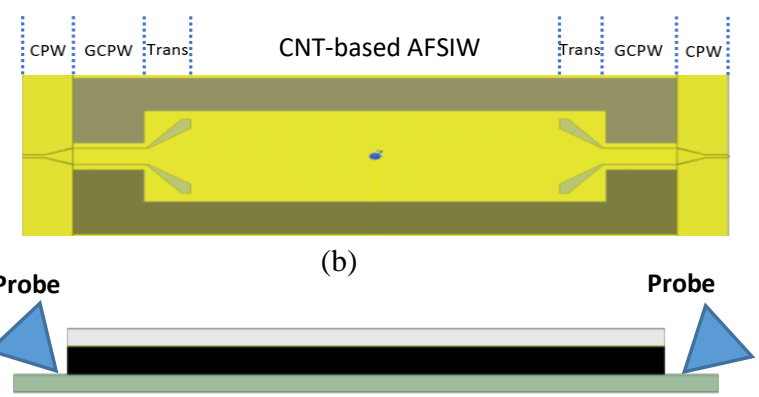

(c)

Fig. 2. CNT-based AFSIW with the transition of planar access. a) 3-D view. b) Top view. c) Cross-section view.

\section{B. Design of the SIW transition}

In the literature, achieving a high-performance transition between coplanar access and SIW waveguide is a challenge for all SIW designers. Many transition topologies have been studied and developed in recent years. Focusing on monolayer substrates, one of the most efficient transition is the GCPW-SIW. The principle is to progressively widen a coplanar line with a ground plane so that the width of the central ribbon approaches the width of the waveguide. The coupling takes place through a $1 / 4$-wavelength triangular slot as presented in [7], leading to a matching better than $20 \mathrm{~dB}$ on a wide bandwidth of $80 \%$ around $13 \mathrm{GHz}$.

In order to feed the proposed waveguide, a transition was designed and simulated based on the transition design in [7]. It should be emphasized that, for this SIW waveguide, the electrical energy is contained in the air inside the guide while it is essentially contained in RT Duroid substrate in the CPW feeding section. Therefore, a direct transition from a CPW access line on Duroid substrate directly to the waveguide is not possible. An intermediate path, via a GCPW line in the air, is needed to ensure a smoother transition, as illustrated on Fig. 2. The metallic cover of the CNT-based AFSIW waveguide will also serve as a ground plan to the GCPW access line with air as a dielectric between the ground plan and the CPW line.

Fig. 3 is a detailed view of the developed CPW-GCPWAFSIW transition, which was designed and optimized to minimize insertion losses within the E-band. The first step is to optimize the CPW-GCPW transition. The dimension of these lines are designed and optimized so that each line has a characteristic impedance equal to $50 \Omega$ with a gap of at least $10 \mu \mathrm{m}$ (minimum dimension for the subsequent technological realization) which allows a test with probes of $100 \mu \mathrm{m}$-pitch. Optimized dimensions are as follows: $W_{C P W}=78 \mu \mathrm{m}, W_{s 1}=$ $10 \mu \mathrm{m}, d=150 \mu \mathrm{m}, W_{G C P W}=480 \mu \mathrm{m}, W_{s 2}=25 \mu \mathrm{m}$.

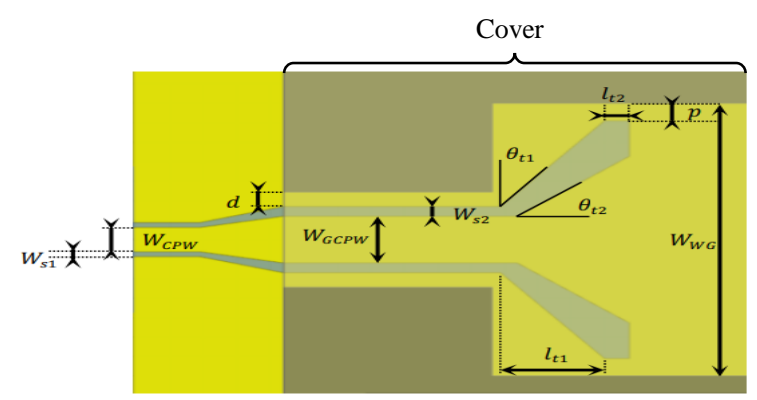

Fig. 3. Detailed view of large bandwidth CPW-GCPW-CNT-based AFSIW transition.

The geometry of the GCPW-SIW transition is defined by two angles $\theta_{t 1}$ and $\theta_{t 2}$ as well as by the lengths $l_{t 1}$ and $l_{t 2}$. The distance $p$ between the end of the transition and the lateral wall of CNT is also defined. Ideally, the length of the triangular slot should be one-quarter of wavelength at the center frequency of the E-band $(0.95 \mathrm{~mm}$ at $78.5 \mathrm{GHz})$. The optimized dimensions of the transitions are given by $l_{t 1}=$ $0.62 \mathrm{~mm}, l_{t 2}=0.15 \mathrm{~mm}, \theta_{t 1}=35^{\circ}, \theta_{t 2}=38^{\circ}, p=0.25 \mathrm{~mm}$.

\section{Simulation results}

In practice, the extraction of the propagation constant will be performed through a de-embedding algorithm [8] requiring sets of $\mathrm{S}$-parameters for different lengths of waveguides. Ideally, the extraction should be done using two different waveguides whose electrical length differ by 90 degrees at the center frequency [9]. For these reasons, five different lengths were implemented following the rule given 
by equation (1):

$$
L_{i}=L_{0}+i \Delta L \quad 0 \leq i \leq 4
$$

where $L_{0}$ stands for the waveguide length of the shortest feature ("Thru") and $\Delta L=0.9 \mathrm{~mm}$ is close to a quarter of guided wavelength at center frequency. Therefore, the attenuation constant can be estimated with a better accuracy by comparison of the longest waveguide with the shortest. The simulated results obtained for different lengths of investigated waveguides and the extracted values of the propagation constant are illustrated in Fig. 4 and Fig. 5, respectively.

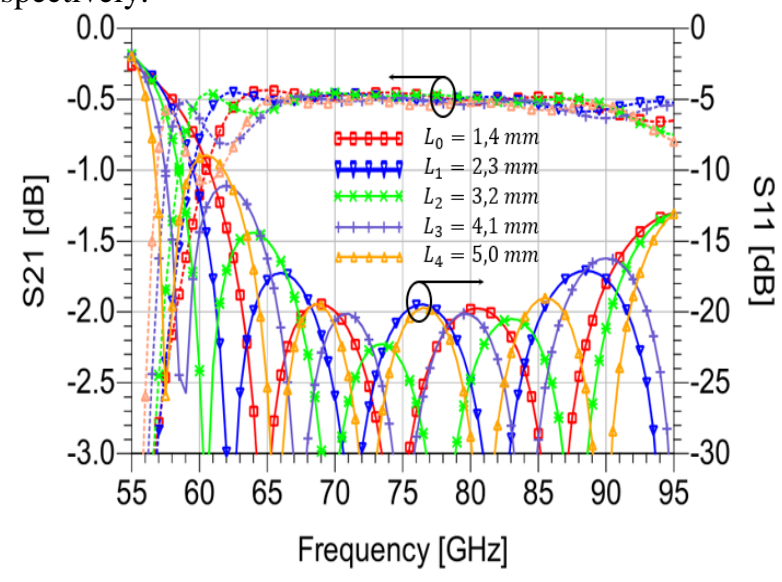

Fig. 4. Simulated S-parameters of five different waveguides with its access line and transitions.
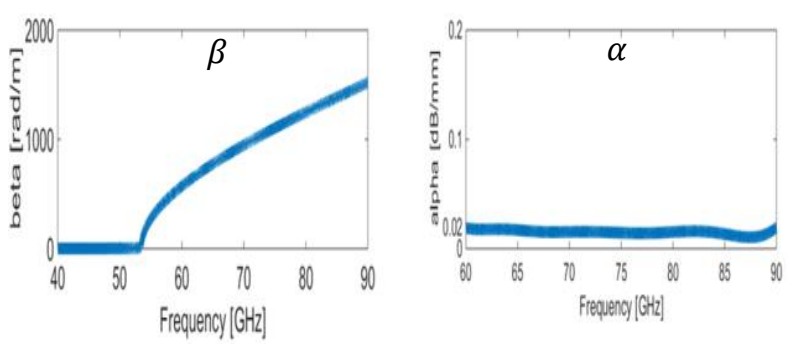

Fig. 5. Extracted values of the simulated phase constant and the attenuation constant of investigated waveguides after de-embedding technique [8].

As shown in Fig. 4, the expected matching is better than 15 $\mathrm{dB}$ over the band $\mathrm{E}$ for all structures, meanwhile the simulated insertion loss including transitions is lower than $0.6 \mathrm{~dB}$. After de-embedding, the maximum expected attenuation constant is about $0.02 \mathrm{~dB} / \mathrm{mm}$ for the whole Eband $(71-86 \mathrm{GHz})$. By considering these promizing simulated results, couplers and crossovers have been optimized (see section V) to address the BM (section VI). These first simulated results will have to be checked once the AFSIW will have been fabricated in the proposed technology.

\section{CNT-BAsed Afsiw Hybrid COUPLER AND CROSSOVER DESIGNS}

In this section, E-band AFSIW hybrid coupler and crossover using CNT-lateral walls are introduced, based on the short-slot coupler topology proposed for SIW in [10]. Fig. 6 illustrates the implementation of these structures. The geometrical parameters are the width of the waveguide access, $W_{a}$, the width and the length of the central waveguide, $W$ and $L$, and the coupling length, $L^{\prime}$. The width of the CNT lateral wall, $W_{C N T}$, was chosen at least $1 \mathrm{~mm}$ for fabrication purpose.

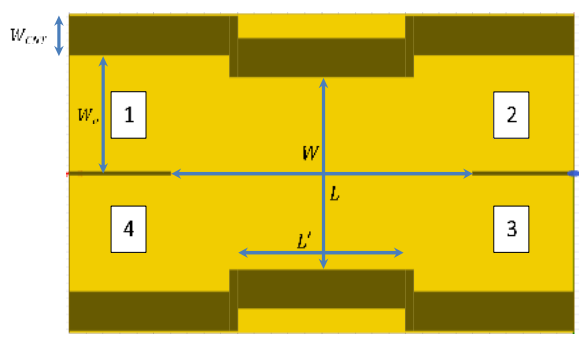

Fig. 6. Topology of short-slot coupler in SIW.
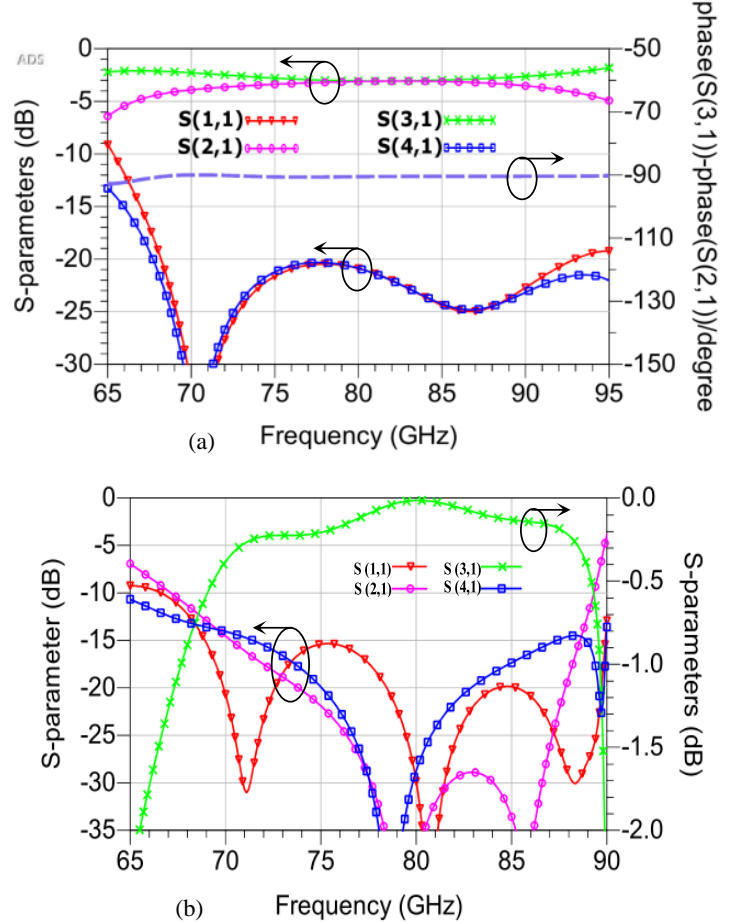

Fig. 7. (a) Simulated S-parameter and amplitude imbalance of the optimized AFSIW 3-dB coupler. (b) Simulated S-parameter of the optimized AFSIW crossover.

After optimization, the 3-dB coupler presents the following dimensions: $W=5 \mathrm{~mm}, L=2 \mathrm{~mm}$ et $L^{\prime}=3.6 \mathrm{~mm}$. Meanwhile, the crossovers were optimized for $W=5.19 \mathrm{~mm}$, $L=5.19 \mathrm{~mm}$ et $L^{\prime}=7.69 \mathrm{~mm}$. Fig. 7 illustrates the simulation results for these two couplers. In both cases, matching is greater than $15 \mathrm{~dB}$ over the range $71-86 \mathrm{GHz}$. At the center frequency of $78.5 \mathrm{GHz}$, the expected insertion losses are $0.1 \mathrm{~dB}$ for the $3-\mathrm{dB}$ coupler and $0.05 \mathrm{~dB}$ for the crossover. The unbalance for the $3-\mathrm{dB}$ coupler is less than $0.63^{\circ}$ in phase over the entire E-band, and remains less than $1 \mathrm{~dB}$ in amplitude between 73 and $86 \mathrm{GHz}$. This allows us to predict a correct operation over the E-band for this Butler matrix.

\section{CNT-BASED Afsiw Butler MAtrix Simulation}

By combining the previous results on Keysight ADS and optimizing the length of the phase shifters, the simulation results of the BM are illustrated in amplitude and phase in Fig. 8. Due to the symmetry of the BM, only port 1 and port 2 were excited. A matching and an isolation between input ports greater than $15 \mathrm{~dB}$ for both excitations can be expected (see Fig. 8). Focusing on a restricted frequency band from 76 to $86 \mathrm{GHz}$, the input-output transmission for excitation on port 1 is $6.7 \pm 0.7 \mathrm{~dB}$ with a maximum phase error of $1.8^{\circ}$ while for excitation on port 2 it is $6.4 \pm 1.2 \mathrm{~dB}$ with a maximum phase error of $3.7^{\circ}$. 

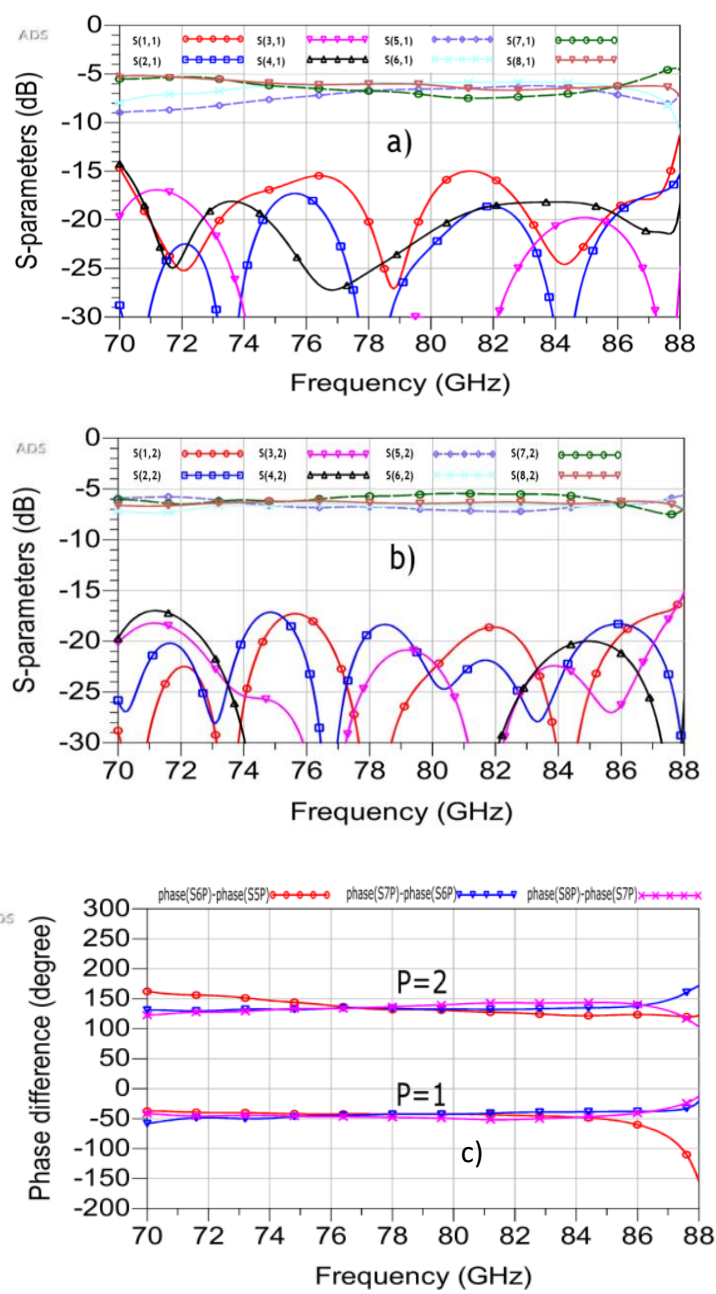

Fig. 8. Simulated S-parameters in amplitude with excitation on port 1 in (a) and on port 2 in (b). Phase difference according to the input ports (c).

\section{FABRICATION OF CNT-BASED AFSIW WAVEGUIDE}

Fig. 9 represents the layout sent to Nanyang University, in Singapore, for the first fabrication by the laboratory UMICINTRA-NTU. Fabricated structures will include waveguides and calibration kits, fitted on a 4-inch diameter wafer.

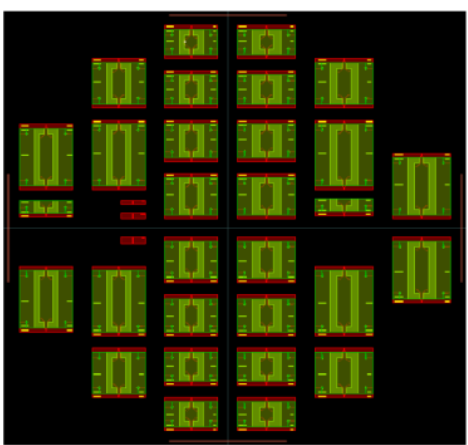

Fig. 9. Layout of investigated waveguides and calibration kits in CNT technology.

\section{CONCLUSION AND DISCUSSIONS}

The interest of the CNT technology has been proposed in this paper to design a low-loss E-band AFSIW Butler matrix. The basic blocks (waveguides, 3-dB coupler and crossover will be manufactured in Singapore as part of the ANR TRICOT project) to validate the expected low losses. The transitions that interconnect waveguides to planar feeding lines have also been presented in this paper.

The first simulation results of the $\mathrm{BM}$ are very encouraging, in particular in the $76-86 \mathrm{GHz}$ band, since low loss and low phase imbalances are expected, which should lead to state-of-art performance at such frequencies as compared to [10] showing $2.5 \mathrm{~dB} \pm 1 \mathrm{~dB}$ of insertion loss at $60 \mathrm{GHz}$ or [11] showing comparable simulated performance in terms of insertion loss $(0.7 \pm 0.75 \mathrm{~dB}$ between 72 and $81 \mathrm{GHz}$ ) but with a phase imbalance of $7^{\circ}$. In the proposed structure of AFSIW, the expected low-loss is due to both the low conductive loss of carbon nanotubes (parameter which will have to be confirmed by the measurements), combined with the air-filled topology, while better phase control comes for the simplicity and perfect symetry of the structure as compared to [11]. However, it must be noticed that below 76 $\mathrm{GHz}$, the amplitude imbalance of couplers deteriorates the performance. Hence, the couplers should be slightly optimized at low frequencies.

\section{REFERENCES}

[1] J. G. Andrews et al., "What will 5G be?," IEEE J. Sel. Areas Commun., vol. 32, no. 6, pp. 1065-1082, 2014.

[2] Z. Haisong, "Second-generation E-Band for LTE backhaul," SoftMobile, pp. 27-28.

[3] S. Peleg, "The Advantages of E-Band Wireless Systems in Mobile Backhaul Applications," Siklu Inc, Petach-Tikva, vol. 44, no. March, 2009.

[4] Q. L. Yang, Y. L. Ban, K. Kang, C. Y. D. Sim, and G. Wu, "SIW Multibeam Array for 5G Mobile Devices," IEEE Access, vol. 4, pp. 2788-2796, 2016.

[5] A. Ghiotto, F. Parment, T. Martin, T. P. Vuong, and K. Wu, "Airfilled substrate integrated waveguide - A flexible and low loss technological platform," 2017 13th Int. Conf. Adv. Technol. Syst. Serv. Telecommun. TELSIKS 2017 - Proceeding, vol. 2017-Octob, pp. 147-149, 2017.

[6] P. Franck, D. Baillargeat, and B. K. Tay, "Mesoscopic model for the electromagnetic properties of arrays of nanotubes and nanowires: A bulk equivalent approach," IEEE Trans. Nanotechnol., vol. 11, no. 5, pp. 964-974, 2012.

R. Kazemi, A. E. Fathy, S. Yang, and R. A. Sadeghzadeh, "Development of an ultra wide band GCPW to SIW transition," RWW 2012 - Proc. IEEE Radio Wirel. Symp. RWS 2012, pp. 171174, 2012.

P. Souzangar and M. Shahabadi, "Numerical Multimode ThruLine ( TL ) Calibration Technique for Substrate Integrated Waveguide Circuits," vol. 5071, 2012.

G. F. Engen and C. A. Hoer, "Thru-Reflect-Line: An Improved Technique for Calibrating the Dual Six-port Automatic Network Analyzer," 1979.

C. J. Chen and T. H. Chu, "Design of 60-GHz SIW short-slot couplers," APMC 2009 - Asia Pacific Microw. Conf. 2009, no. c, pp. 2096-2099, 2009.

[11] T. Djerafi and K. Wu, "A low-cost wideband 77-ghz planar butler matrix in siw technology," IEEE Trans. Antennas Propag., vol. 60, no. 10, pp. 4949-4954, 2012. 